\title{
Comparing the Effect of Arabic, Basil Seed and Salvia Macrosiphon Gums-Based Coatings on the Shelf-Life of Tomatoes
}

\author{
Zahra Pourshaab Fallah ${ }^{1}$, Ali Motamedzadegan ${ }^{2}$, Mahsa Mohammadi Haghighi ${ }^{3}$, Zahra Latifi ${ }^{4}$, \\ and Sepideh Gholami Khesht ${ }^{5,6}$ \\ ${ }^{1}$ Faculty of Agriculture and Food Science, Islamic Azad University, Ayatollah Amoli Branch, Amol 678, Iran \\ ${ }^{2}$ Department of Food Science and Technology, Sari Agriculture and Natural Resources University, Sari 48181-66996, Iran \\ ${ }^{3}$ Department of Food Science and Technology, Islamic Azad University, Nour Branch, Nour 4641859557, Iran \\ ${ }^{4}$ Young Researchers and Elites Researchers Club, Islamic Azad University, Sari Branch, Sari 48164-194, Iran \\ ${ }^{5}$ Novin Saffron Company, Mashhad 9185184186, Iran \\ ${ }^{6}$ Department of Food Science and Technology, Ferdowsi University, Mashhad 9177948974, Iran
}

\begin{abstract}
A novel edible coating containing basil seed gum (0.1, 0.3, and 0.5\%), Salvia macrosiphon seed gum (0.25, 0.5, and $0.75 \%$ ), and Arabic gum (10\%) at normal $\mathrm{pH}$ and $\mathrm{pH} 5 / 6$ has been used as a postharvest treatment to maintain tomato quality and safety. In this study, the physicochemical properties of tomatoes were investigated during 35 days of storage at $4^{\circ} \mathrm{C}$. During storage, coated fruit showed increases in vitamin $\mathrm{C}$ retention, reduced weight loss, color changes, and accelerated softening. However, treatment of tomatoes with gum significantly delayed onset of parameters related to loss of postharvest quality, and storability was extended. All the coated samples had increased vitamin $\mathrm{C}$ retention compared with controls, with highest contents observed for tomatoes coated in basil seed gum $0.1 \%$ and Arabic gum at pH 5.6. In conclusion, basil seed gum $0.1 \%$, S. macrosiphon seed gum 0.25 and $0.5 \%$, and Arabic gum at normal pH were the best treatments for maintaining postharvest quality of tomatoes.
\end{abstract}

Keywords: Arabic gum, basil seed gum, edible coating, Salvia macrosiphon gum, tomato

\section{INTRODUCTION}

Tomatoes (Solanum lycopersicum L.) are among the most consumed fruits in the world, therefore may be considered essential sources of dietary antioxidants (Lenucci et al., 2006). Tomatoes are climacteric fruits that have relatively short postharvest lives due to many physicochemical changes causing loss of quality. As a climacteric fruit, gas, temperature, and humidity adjustment can regulate tomato fruit ripening. Low-temperature storage is needed to preserve freshness and to extend shelf life, leading to a decreased rate of respiration and reducing thermal decomposition. However, chilling injuries may affect the quality of fruits stored below $12.5^{\circ} \mathrm{C}$ (Bailén et al., 2006; Ali et al., 2010). Controlled atmosphere and hypobaric storage are other approaches that can help extend the shelf-life of tomatoes (Ali et al., 2010). However, these processes are capital intensive and costly to run. Therefore, a cheaper alternative is required to extend posthar- vest life and keep production costs low. Since gums are obtained from various sources and have a wide range of applications, gum-based edible coatings may be desirable candidates (Ali et al., 2010). An edible coating is a thin layer of edible materials, that forms a coating on a food product. Coatings are applied in liquid form, usually by immersing the product in a solution formed by the structural matrix.

Edible films and coatings can protect food products from moisture migration, microbial growth on surfaces, light-induced chemical changes, and nutrient oxidation. Edible coatings can act as barriers against oils, gases, vapors, and carriers of active substances such as antioxidants, antimicrobials, colors, and flavors (Latifi et al., 2019; Ebadi et al., 2021). These functions enhance the quality of food products, resulting in extended shelf-lives and improved safety (Baldwin, 1994; Pérez-Gago et al., 2010). Development of edible coatings using natural biopolymers presents many advantages for the quality char-

Received 6 April 2021; Revised 24 September 2021; Accepted 1 October 2021; Published online 31 December 2021

Correspondence to Mahsa Mohammadi Haghighi, Tel: +98-911-341-3404, E-mail: m.mohammadi.h@gmail.com

Author information: Zahra Pourshaab Fallah (Graduate Student), Ali Motamedzadegan (Professor), Mahsa Mohammadi Haghighi (Researcher),

Zahra Latifi (Graduate Student), Sepideh Gholami Khesht (Researcher) 
acteristics of fruits, allowing alternatives with lower costs and more accessible applications than other conservation systems. Consequently, edible coatings may be an effective alternative to synthetic materials in terms of edibility, biocompatibility, nontoxicity, and lower costs (Krochta et al., 1994). Gums are used in foods due to their different beneficial characteristics. Arabic gum or gum acacia is a dried, gummy exudate from the stems or branches of Acacia species. It is the least viscous and most soluble of the hydrocolloids, and is used extensively in the industrial sector because of its emulsification film-forming properties (Ali et al., 2010). The genus Salvia (Labiatae) comprises more than 700 species, of which 200 grow in Iran. Wild sage seed (Salvia macrosiphon) is a tiny rounded seed, which readily swells in water to give mucilage. Gum extracted from these seeds has been shown to have good thickening properties (Javidnia et al., 2005). Basil seed gum is a novel hydrocolloid extracted from Ocimum basilicum L. seeds. Basil seed gum has shown promising stabilizing and emulsifying properties, making it a potential functional ingredient for the food industry (HosseiniParvar et al., 2010). Many studies have shown that coating has potential to be used as a protective treatment for extending postharvest qualities of fruits and vegetables such as tomatoes (Zapata et al., 2008; Ali et al., 2010), apples (El-Anany et al., 2009), strawberries (Ribeiro et al., 2007), and mangos (Chien et al., 2007). However, no published studies have yet been conducted on the application of basil gum and wild sage seed as edible coating for increasing the storage life of tomatoes. Hence, this study aimed to evaluate the physicochemical properties of coated tomato during storage.

\section{MATERIALS AND METHODS}

\section{Materials}

Tomatoes (S. lycopersicum L. var. Money Maker L.) was collected from Noshahr city (Mazandaran, Iran) in April 2014. Basil and S. macrosiphon seeds were purchased from a reputable local market in Chaloos (Mazandaran, Iran). Arabic gum was purchased from Scharlau (Barcelona, Spain). Glycerol, 2,6-dichlorophenolindophenol, and yeast glucose chloramphenicol culture medium were purchased from Merck KGaA (Darmstadt, Germany). All other chemicals used in this study were of analytical grade and were purchased from chemical suppliers.

\section{Basil seed extraction}

Basil seed gum was extracted following the methods by Razavi et al. (2009). To prepare gum mass, seeds were soaked in water at $68^{\circ} \mathrm{C}$ in a ratio of 1:65. During soaking, a row mixer stirred the mixture for $20 \mathrm{~min}$ at 1,000 rpm. Gum was separated from the swelled seeds by passing the seeds through an extractor (JC 700P, Pars Khazar, Rasht, Iran) with a rough rotating plate that scraped the gum layer on the seed surface. The separated gum was collected, and the residual gum adhered to the seeds was immersed in water with the rotating extractor. The gum collected from the different stages was mixed, filtered, and dried by a vacuum oven at $50^{\circ} \mathrm{C}$. Finally, the dried extracted gum was ground, packed in plastic bags, and stored in dry and cool condition.

\section{S. macrosiphon extraction}

S. macrosiphon seed gum was extracted from whole seeds using distilled water (water to seed ratio of 1:51) at $\mathrm{pH}$ 5.5. The gum from swelled seeds was separated by passing the seeds through a laboratory extractor (Model 412, Pars Khazar). Crude gum was collected, and residual seeds were immersed in the remaining water in two stages, according to the water-to-seed ratio proposed for each run, and passed through the extractor again. The collected crude gum from the different stages was mixed, filtered, and dried overnight in a forced convection oven (Model 4567, Kimia Pars, Tehran, Iran) at $70^{\circ} \mathrm{C}$. The dried gum was ground, filtered, and used for analysis (Bostan et al., 2010).

\section{Preparation of hydrocolloid suspensions}

Coating solutions were prepared according to the method of Ali et al (2010). Basil seed gum and S. macrosiphon gum were separately mixed and distilled in a weight/volume ratio. Suspensions were mixed for $60 \mathrm{~min}$ at $20^{\circ} \mathrm{C}$, then glycerol $1 \%$ was added to increase the strength and flexibility of the coating solutions. The Arabic gum solution was prepared in two ways: (1) without maintaining the $\mathrm{pH}$; (2) maintaining the $\mathrm{pH} 5.6$ by $1 \mathrm{~N} \mathrm{NaOH}$, following by similar stages as those used in the preparation of the other solutions. The concentrations of the prepared solutions were $0.1,0.3$, and $0.5 \%$ for basil seed gum, 0.25 , 0.5 , and $0.75 \%$ for S. macrosiphon seed gum, and $10 \%$ for Arabic gum.

\section{Tomato coatings}

Red tomatoes of the same shape and size, without any mechanical damage and pathogenic contamination, were purchased. Tomatoes were washed with distilled water, rinsed, and dried at an ambient temperature. Then, tomatoes were soaked in the prepared solution for $4 \mathrm{~min}$ at $20^{\circ} \mathrm{C}$ until the whole fruits were coated. Coated fruits were dried at ambient temperatures for 60 min, packaged in polyethylene at $7^{\circ} \mathrm{C}$, with a humidity of $85 \%$ to $90 \%$, and stored for 35 days. Control sample were also prepared in a similarly manner but without coatings. All tomatoes were analyzed for physicochemical and microbial properties at intervals of 7 days (Ali et al., 2010). 


\section{Weight loss determination}

Tomatoes were weighed at day 0 and at the end of each storage interval. Total weight loss during that storage interval was calculated as the difference between the initial and final weights, calculated as percentages of a fresh weight based on the standard Association of Official Analytical Chemists (AOAC) method (Helrich, 1990).

\section{Acidity}

Titratable acidity of aliquots was determined by titrating with $0.1 \mathrm{~N} \mathrm{NaOH}$ until a $\mathrm{pH}$ of 8.1 was reached. Titratable acidity was expressed as mg of citric acid per $100 \mathrm{~g}$ of fresh fruit.

\section{Determination of $\mathrm{pH}$}

An industrial juicer (G100, Hellal, Tehran, Iran) was used to extract the tomato juice. To determine the $\mathrm{pH}$ of the juice, a pH meter (Model 691, Metrohm AG, Herisau, Switzerland) was used. The juice was poured into beakers containing $\mathrm{pH}$ meter electrodes to record the $\mathrm{pH}$ of the juice.

\section{Determination of total soluble solids (TSS)}

Tomatoes were ground in a blender, and the juice was used to determine the concentration of soluble solids (Brix) using a Digital Refractometer (Model PR-32, Atago, Tokyo, Japan).

\section{Determination of ascorbic acid content}

Ascorbic acid contents were determined following the method of AOAC (Helrich, 1990). Ground samples were weighed into $50 \mathrm{~mL}$ tubes, mixed with $25 \mathrm{~mL}$ of $2.5 \%$ $m$-phosphoric acid using a vortex mixer for $1 \mathrm{~min}$, and centrifuged for $20 \mathrm{~min}$ at $48^{\circ} \mathrm{C}$ and $3,000 \mathrm{~g}$. The supernatant was filtered through a cheesecloth into $50 \mathrm{~mL}$ volumetric flasks, and ascorbic acid contents were determined using 2,6-dichlorophenolindophenol titration.

\section{Statistical analyses}

All analyses were carried out in triplicate. Data were subjected to analysis of variance (ANOVA). Sources of variation were storage time and treatment. Mean comparisons were performed using Duncan's post-hoc tests to examine if differences between treatments and storage times were significant at $P<0.05$. All analyses were performed using SPSS software package version 16.0 for Windows (SPSS Inc., Chicago, IL, USA).

\section{RESULTS AND DISCUSSION}

\section{Weight loss measurements}

The effect of Arabic gum, basil seed gum, and S. macrosiphon gum coating on weight loss of tomatoes stored for

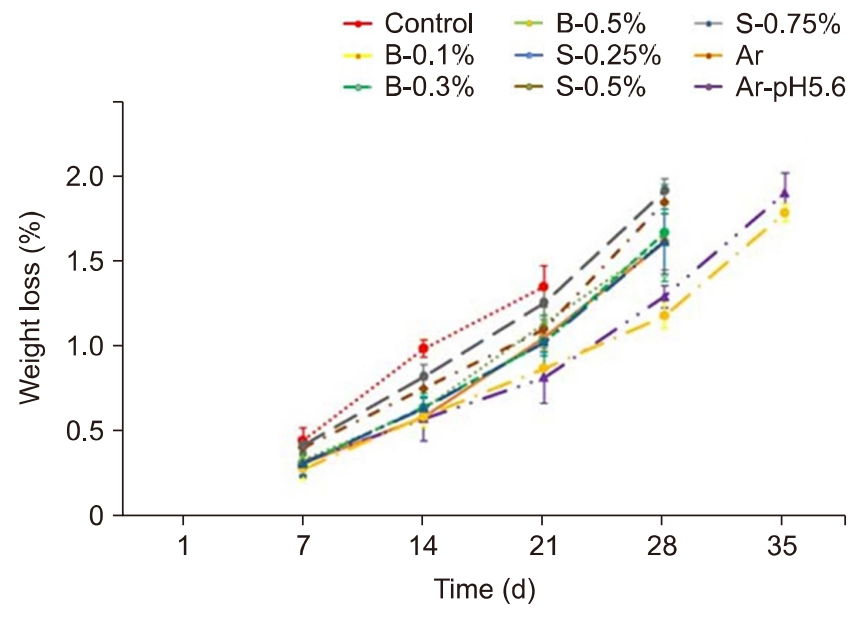

Fig. 1. Changes in weight loss of tomatoes with different coatings during the 35 days of storage. Results are presented as mean \pm standard deviation. Ar, Arabic gum; B, basil seed gum; S, Salvia macrosiphon seed gum.

35 days is shown in Fig. 1. Weight loss of control fruits significantly $(P<0.05)$ increased with storage time, reaching $2.8 \%$ at day 35 (Fig. 1). Coated fruits showed less weight loss during storage than controls, and with only gradual increases during the storage period. The results indicated that gums significantly $(P<0.05)$ reduced weight loss and acted as a barrier against water loss. The primary mechanism of weight loss from fresh fruit and vegetables is vapor pressure from different locations (Yaman and Bayoundirl, 2002), although respiration also causes weight reductions. The reduction in weight loss was probably due to the effects of the coating as a semipermeable barrier against $\mathrm{O}_{2}, \mathrm{CO}_{2}$, moisture, and solute movement, thereby reducing respiration, water loss, and rates of oxidative reactions (Baldwin et al., 1999).

These results are in agreement with findings from Srinivasa et al. (2006) on tomatoes and bell peppers packaged in cartons covered with eco-friendly chitosan film or synthetic petroleum-based low-density polyethylene (LDPE) film. In this study, chitosan and LDPE films extended the storage life of both tomatoes and bell peppers through reducing water loss and modifying the internal atmosphere. Similar results were reported by Lim et al. (2011), who used gelatin, carboxymethylcellulose, and soy protein isolates as edible films at three different concentrations for coating sweet cherry (Prunus avium L.) fruits. This study reported that coating significantly decreased moisture loss from coated fruits, decreasing their weight loss (Lim et al., 2011). Martínez-Romero et al. (2006) observed similar results when they coated sweet cherry fruits using aloe vera as a novel edible coating. Another study by Jafarizadeh Malmiri et al. (2011) showed the effect of three edible coating formulations on the peel surface of mature green bananas, which were stored at $26^{\circ} \mathrm{C}$ with relative humidity ranging from $40 \%$ to $50 \%$. The authors showed that coated bananas with $1.5 \%$ so- 
dium carboxymethyl cellulose had negligible weight loss and TSS contents (Martínez-Romero et al., 2006). Furthermore, a study by Saekow et al. (2019) indicated that applying carboxymethyl cellulose coatings combined with $\mathrm{ZnO}$ nanoparticles to tomatoes decreases the rate of weight loss. Corn starch and carnauba wax coatings have also been reported to be effective moisture barriers and to reduce weight loss of coated tomatoes (Fitch-Vargas et al., 2019). In addition, coating tomatoes with red algae and brown algae decreased weight loss during a 28 day storage period (Banu et al., 2020), and Khalil et al. (2020) indicated that glycerol, starch, and gelatin amalgamated with gamma-irradiated Lactobacillus bacteria as an edible coating gave better results than untreated fruits, such as diminishing weight loss. Moreover, a study by Ruiz-Martínez et al. (2020) showed that edible coatings of candelilla wax with Flourensia cernua extract reduces weight and loss of firmness of tomatoes, and Zhu et al. (2019) revealed that nano-SiOx/chitosan complex coatings result in lower weight loss of green tomato compared with chitosan and controls. Finally, a study by Sganzerla et al. (2021) showed that carboxymethyl cellulose-based film enriched with blackberry anthocyanin-rich extract helps preserve cherry tomatoes and helps maintain their weights.

\section{Acidity evaluation}

The control tomatoes had a slightly higher acid content compared with the coated fruits (Table 1), although the rates of acid content changes did not significantly differ $(P>0.05)$. However, the difference between the acid contents of the coated and control fruits was significant during storage $(P<0.05)$. In previous studies, Yaman and Bayoundirlt (2002), Dong et al. (2004), and Durrant and Dong (2004), reported slow rates of decreasing acidity for litchi, cherries, and peach. Organic acids are substrates for many enzyme-catalyzed reactions during aerobic respiration in plant cells, and reductions in acidity may be expected as a result of such activity during the ripening process, thus making the fruits taste relatively more sweet. A decline in acidity indicates increased maturation; thus, coating delayed fruit maturation/ripening. Citric acid is one of the primary substances of respiration; during the storage period, total acidity decreases due to oxidation, but the acidity in the fruit increases. However, another experiment on organic papaya fruit showed that gums helped preserve the fruit acids compared with control treatment (Eskandari et al., 2014). In a study by Fitch-Vargas et al. (2019), tomatoes coated with corn starch and carnauba wax had a lower percentage of titratable acidity than control fruit, and in a study where seaweeds, namely red algae and brown algae, were used to coat tomatoes to control total acidity, lowest acidities were reported for control samples (Banu et al., 2020). In addition, another study by Khalil et al. (2020) using irradiated Lactobacillus paracasei cell-free supernatants combined with glycerol, starch, and gelatin as edible coatings for control samples had lower percentages of titratable acids than coated samples. Furthermore, Ruiz-Martínez et al. (2020) showed that coating tomatoes with candelilla wax containing $F$. cernua extract resulted in minimal percentages of titratable acidity. Moreover, a study by Sganzerla et al. (2021) reported that carboxymethyl cellulose-based coatings enriched with blackberry extract did not alter acidity during storage and, therefore, the parameter for all the samples was the parameter gradually decreased during storage.

\section{pH measurements}

The $\mathrm{pH}$ depends on the concentration of hydrogen ions in the solution. The $\mathrm{pH}$ of tomatoes was increased during storage (Fig. 2). Since coated fruits showed minor variation in titratable acidity, the associated variations in their $\mathrm{pH}$ values were also relatively low. Control tomatoes had a higher $\mathrm{pH}$ than coated fruits at any given time, confirming previous results from Maftoonazad and Ramaswamy (2005) showing increasing $\mathrm{pH}$ values in avocados coated with methyl cellulose-based. The rates of $\mathrm{pH}$ increases was also higher in control samples than in coated fruits. Toğrul and Arslan (2004) showed increases in $\mathrm{pH}$ values of samples with different coating during storage. Furthermore, Fitch-Vargas et al. (2019) showed that carnauba

Table 1. Changes in acidity of tomatoes with different coatings during 35 days of storage

\begin{tabular}{|c|c|c|c|c|c|c|c|c|c|}
\hline $\begin{array}{l}\text { Day of } \\
\text { storage }\end{array}$ & Control & $\begin{array}{l}\text { Ar-pH } \\
\text { Normal }\end{array}$ & $\mathrm{Ar}-\mathrm{pH} 5.6$ & B- $0.1 \%$ & B- $0.3 \%$ & B- $0.5 \%$ & S-0.25\% & S-0.5\% & S-0.75\% \\
\hline 1 & $0.48 \pm 0.02^{\mathrm{a}}$ & $0.46 \pm 0.01^{a}$ & $0.44 \pm 0.04^{a}$ & $0.47 \pm 0.01^{a}$ & $0.47 \pm 0.03^{a}$ & $0.46 \pm 0.03^{\mathrm{a}}$ & $0.44 \pm 0.02^{a}$ & $0.47 \pm 0.03^{a}$ & $0.48 \pm 0.02^{a}$ \\
\hline 7 & $0.42 \pm 0.01^{b}$ & $0.42 \pm 0.00^{b}$ & $0.42 \pm 0.04^{\mathrm{ab}}$ & $0.45 \pm 0.02^{\mathrm{ab}}$ & $0.44 \pm 0.02^{\mathrm{ab}}$ & $0.43 \pm 0.03^{\mathrm{ab}}$ & $0.41 \pm 0.01^{b}$ & $0.43 \pm 0.03^{\mathrm{ab}}$ & $0.43 \pm 0.02^{\mathrm{a}}$ \\
\hline 14 & $0.37 \pm 0.01^{c}$ & $0.39 \pm 0.01^{\text {bc }}$ & $0.40 \pm 0.04^{\mathrm{ab}}$ & $0.43 \pm 0.02^{\mathrm{bc}}$ & $0.41 \pm 0.03^{\mathrm{bc}}$ & $0.40 \pm 0.03^{\mathrm{ab}}$ & $0.38 \pm 0.01^{c}$ & $0.39 \pm 0.02^{b c}$ & $0.43 \pm 0.06^{b}$ \\
\hline 21 & $0.30 \pm 0.00^{d}$ & $0.35 \pm 0.03^{c}$ & $0.38 \pm 0.03^{\mathrm{abc}}$ & $0.41 \pm 0.01^{c d}$ & $0.38 \pm 0.02^{c d}$ & $0.37 \pm 0.03^{b c}$ & $0.35 \pm 0.01^{d}$ & $0.34 \pm 0.02^{c d}$ & $0.39 \pm 0.05^{b c}$ \\
\hline 28 & - & $0.32 \pm 0.02^{d}$ & $0.35 \pm 0.30^{b c}$ & $0.39 \pm 0.01^{\mathrm{de}}$ & $0.34 \pm 0.02^{d}$ & $0.33 \pm 0.03^{c}$ & $0.30 \pm 0.00^{\mathrm{e}}$ & $0.29 \pm 0.02^{d}$ & $0.34 \pm 0.04^{c}$ \\
\hline 35 & - & - & $0.32 \pm 0.03^{c}$ & $0.36 \pm 0.01^{\mathrm{e}}$ & - & - & - & - & - \\
\hline
\end{tabular}

Results are presented as mean \pm standard deviation.

The same letters $(a-e)$ in each row indicate that there is no significant difference $(P<0.05)$.

$\mathrm{Ar}$, Arabic gum; B, basil seed gum; S, Salvia macrosiphonseed gum. 


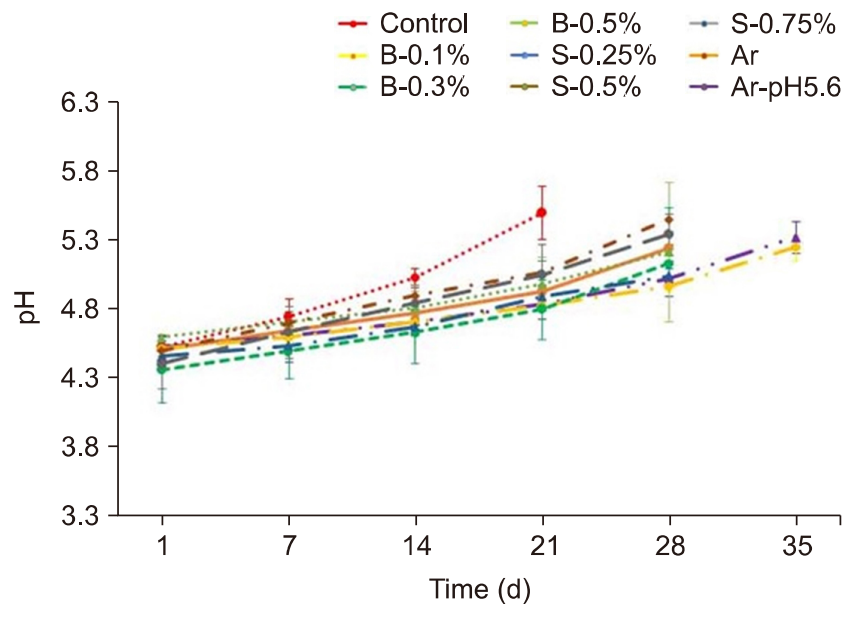

Fig. 2. Changes in $\mathrm{pH}$ of tomatoes with different coatings during 35 days of storage. Results are presented as mean \pm standard deviation. Ar, Arabic gum; B, basil seed gum; S, Salvia macrosiphon seed gum.

wax is a more effective coating for tomatoes than corn starch for inhibiting $\mathrm{pH}$ growth during 20 days of storage, however, both coatings functioned better than the control sample. Moreover, Khalil et al. (2020) revealed that glycerol, starch, and gelatin-based coatings enriched with irradiated $L$. paracasei cell-free supernatant for did not affect the $\mathrm{pH}$ of coated tomatoes compared with control samples during 14 days of storage. In a study where tomatoes were coated with candelilla wax, the $\mathrm{pH}$ was higher than in control tomatoes, and enriching the coating with $F$. cernua extract surged the $\mathrm{pH}$ to the minimum at the end of the storage period (Ruiz-Martínez et al., 2020). In addition, in a study where cherry tomatoes were coated with carboxymethyl cellulose-based coating containing blackberry extract, samples coated with the highest percentage of the extract had the lowest $\mathrm{pH}$ at the end of 15 days storage period (Sganzerla et al., 2021).

\section{TSS measurements}

TSS are an indirect indication of the level of soluble sugars and, therefore, sweetness, and are an important quality characteristic of most fruits since the value will affect the fruit's flavor and marketability (Shwartz et al., 2009). In this study, TSS decreased during storage, with the amount of soluble solids reducing during respiration (Fig. 3). Ali et al. (2010) reported that use of Arabic gum at $10 \%$ delayed changes to the concentration of soluble solids compared with uncoated fruits, similar to the result of the current study. Other studies have reported a gradual decrease in TSS with storage time (Maftoonazad and Ramaswamy, 2005). For example, Fitch-Vargas et al. (2019) showed that during a 20 days storage period, TSS of tomatoes coated with corn starch and carnauba wax did not significantly differ from controls until the second half of the storage period, with all samples showing significant differences on the last day of this period. In an-

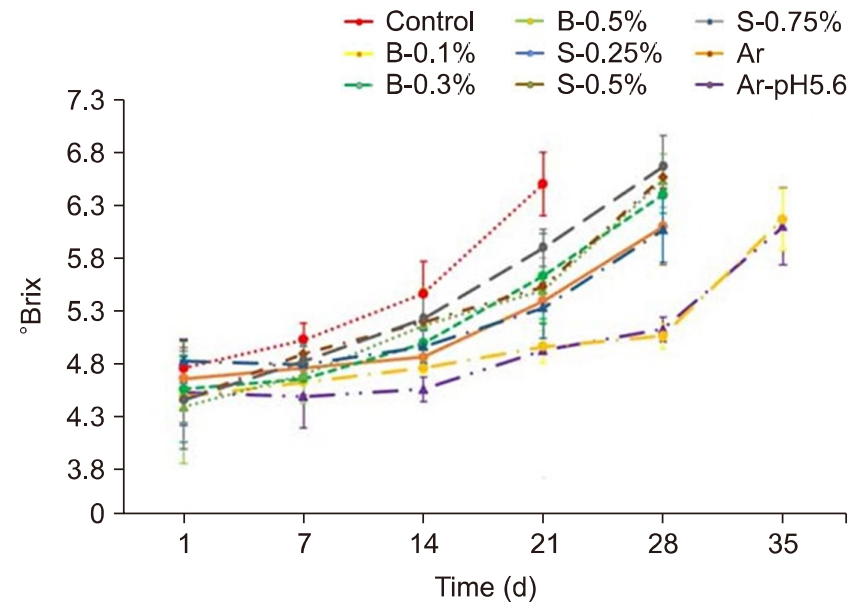

Fig. 3. Changes in total soluble solids of tomatoes with different coatings during 35 days of storage. Results are presented as mean \pm standard deviation. Ar, Arabic gum; B, basil seed gum; S, Salvia macrosiphon seed gum.

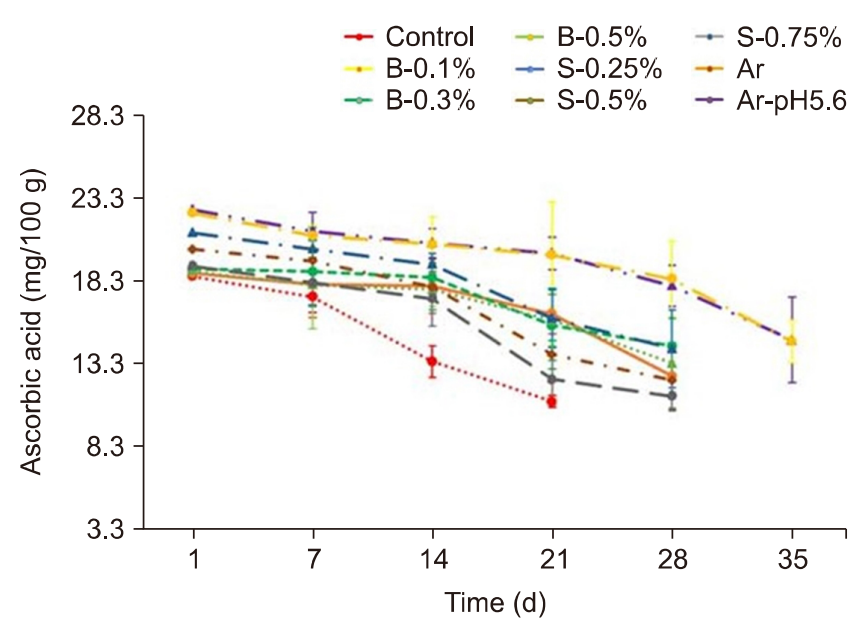

Fig. 4. Changes in ascorbic acid contents of tomatoes with different coatings during 35 days of storage. Results are presented as mean \pm standard deviation. Ar, Arabic gum; B, basil seed gum; S, Salvia macrosiphon seed gum.

other study, coating tomatoes with high concentrations of red and brown algae led to high soluble solids contents during 28 day storage periods (Banu et al., 2020). Furthermore, in the study by Khalil et al. (2020), the TSS percentage increased proportionally with increased storage period, and at each checkpoint untreated tomatoes had higher TSS values than tomatoes coated with glycer$\mathrm{ol}$, starch, and gelatin. In addition, in the study of RuizMartínez et al. (2020), a gradual increase in soluble solids concentration of tomatoes was observed during the storage period, and samples coated with candelilla waxbased coating enriched with $F$. cernua extract had the highest TSS. Moreover, the study of Zhu et al. (2019) revealed that nano-SiOx/chitosan complex film delays loss of TSS.

\section{Ascorbic acid content}

Tomatoes are important sources of vitamin $\mathrm{C}$, which 
varies between 10 and $60 \mathrm{mg}$. Polyphenol oxidase enzymes degrade the fruit, and the content of ascorbic acid decreases during storage. The ascorbic acid (vitamin C) content of coated and uncoated tomatoes decreased during storage, with highest levels of ascorbic acid observed in those coated with $0.1 \%$ basil gum (Fig. 4). In tomatoes, ascorbic acid content increases with maturity and ripening; however, once the fruit is fully ripe, the ascorbic acid content starts to decline. The slower increases in ascorbic acid contents of coated fruit suggests that the coating slows down but does not prevent synthesis of ascorbic acid during ripening. A similar effect on slowing down the increase in ascorbic acid during ripening of tomatoes has been reported with high $\mathrm{CO}_{2}$ storage atmospheres.

In conclusion, edible coatings improved certain quality attributes of tomatoes. Arabic gum, basil seed gum, and S. macrosiphon seed gum increased vitamin $\mathrm{C}$ retention of tomatoes compared with uncoated tomatoes, and helped maintain fruit firmness throughout storage. Combining these gums could be recommended for commercial purposes as an alternative to postharvest chemical treatments, helping to combat the high economic costs and improve the physicochemical properties of tomatoes. In a previous study, while control tomatoes had the lowest ascorbic acid content, tomatoes coated with carboxymethyl cellulose and carboxymethyl cellulose combined with ZnO-nanoparticles had the second-highest and highest contents of ascorbic acid, respectively (Saekow et al., 2019). Furthermore, there is a drastic decrease in the ascorbic acid content of control tomatoes during the storage period; in another study, tomatoes coated with high concentrations of red and brown algae had higher ascorbic acid contents compared with other tomatoes (Banu et al., 2020). Another study revealed that tomatoes coated with glycerol, starch, and gelatin-based coatings amalgamated with gamma-irradiated Lactobacillus bacteria had, in general, high ascorbic acid concentrations during 14 day storage periods (Khalil et al., 2020).

\section{AUTHOR DISCLOSURE STATEMENT}

The authors declare no conflict of interest.

\section{REFERENCES}

Ali A, Maqbool M, Ramachandran S, Alderson PG. Gum arabic as a novel edible coating for enhancing shelf-life and improving postharvest quality of tomato (Solanum lycopersicum L.) fruit. Postharvest Biol Technol. 2010. 58:42-47.

Bailén G, Guillén F, Castillo S, Serrano M, Valero D, MartínezRomero D. Use of activated carbon inside modified atmosphere packages to maintain tomato fruit quality during cold storage. J Agric Food Chem. 2006. 54:2229-2235.

Baldwin EA. Edible coatings for fresh fruits and vegetables: past, present, and future. In: Krochta JM, Baldwin EA, NisperosCarriedo MO, editors. Edible Coatings and Films to Improve Food Quality. CRC Press, Boca Raton, FL, USA. 1994. p 25.

Baldwin EA, Burns JK, Kazokas W, Brecht JK, Hagenmaier RD, Bender RJ, et al. Effect of two edible coatings with different permeability characteristics on mango (Mangifera indica L.) ripening during storage. Postharvest Biol Technol. 1999. 17:215226.

Banu AT, Ramani PS, Murugan A. Effect of seaweed coating on quality characteristics and shelf life of tomato (Lycopersicon esculentum mill). Food Sci Hum Wellness. 2020. 9:176-183.

Bostan A, Razavi SMA, Farhoosh R. Optimization of hydrocolloid extraction from wild sage seed (Salvia macrosiphon) using response surface. Int J Food Prop. 2010. 13:1380-1392.

Chien PJ, Sheu F, Yang FH. Effects of edible chitosan coating on quality and shelf life of sliced mango fruit. J Food Eng. 2007. 78:225-229.

Dong H, Cheng L, Tan J, Zheng K, Jiang Y. Effects of chitosan coating on quality and shelf life of peeled litchi fruit. J Food Eng. 2004. 64:355-358.

Durrant WE, Dong X. Systemic acquired resistance. Annu Rev Phytopathol. 2004. 42:185-209.

Ebadi M, Latifi Z, Daneshniya M. Optimization of the antioxidant effect of ethanolic extract of thistle (Carduus pycnocephalus L.) by response surface method and comparison of the antioxidant effect of extract and essential oil on oxidative soybean oil resistance. Iran J Food Sci Technol. 2021. 17:149-162.

El-Anany AM, Hassan GFA, Ali FMR. Effects of edible coatings on the shelf-life and quality of Anna apple (Malus domestica Borkh) during cold storage. J Food Technol. 2009. 7:5-11.

Eskandari A, Heidari M, Daneshvar MH, Taheri S. Studying effects of edible coatings of Arabic Gum and olive oil on the storage life and maintain quality of postharvest Sweet Lemon (Citrus lemontta). IJACS. 2014. 7:207-213.

Fitch-Vargas P, Aguilar-Palazuelos E, Vega-García M, ZazuetaMorales J, Calderón-Castro A, Montoya-Rodríguez A, et al. Effect of a corn starch coating obtained by the combination of extrusion process and casting technique on the postharvest quality of tomato. Rev Mex Ing Quím. 2019. 18:789-801.

Helrich K. Official methods of analysis of the Association of Official Analytical Chemists. 15th ed. Association of Official Analytical Chemists, Arlington, VA, USA. 1990. p 1058-1059.

Hosseini-Parvar SH, Matia-Merino L, Goh KKT, Razavi SMA, Mortazavi SA. Steady shear flow behavior of gum extracted from Ocimum basilicum L. seed: effect of concentration and temperature. J Food Eng. 2010. 101:236-243.

Jafarizadeh Malmiri H, Osman A, Tan CP, Abdul Rahman R. Evaluation of effectiveness of three cellulose derivative-based edible coatings on changes of physico-chemical characteristics of 'Berangan' banana (Musa sapientum cv. Berangan) during storage at ambient conditions. Int Food Res J. 2011. 18:1381-1386.

Javidnia K, Miri R, Jamalian A. Composition of the essential oil of Salvia macrosiphon Boiss. from Iran. Flavour Fragr J. 2005. 20: 542-543.

Khalil OAA, Mounir AM, Hassanien RA. Effect of gamma irradiated Lactobacillus bacteria as an edible coating on enhancing the storage of tomato under cold storage conditions. J Radiat Res Appl Sci. 2020. 13:318-330.

Krochta JM, Baldwin EA, Nisperos-Carriedo MO. Edible coatings and films to improve food quality. CRC Press, Boca Raton, FL, USA. 1994. p 305-335.

Latifi Z, Daneshniya M, Khademi F. Effect of preservative of Anarijeh (Froriepia subpinnata) extract on shelf life of silver carp fish (Hypophthalmichthys molitrix) at superchilling temperature $\left(-3^{\circ} \mathrm{C}\right)$. Proceedings of the 4th International Conference on Applied Researches in Science and Engineering. 2019 Oct 19. Brussels, Belgium. Poster no. 147. 
Lenucci MS, Cadinu D, Taurino M, Piro G, Dalessandro G. Antioxidant composition in cherry and high-pigment tomato cultivars. J Agric Food Chem. 2006. 54:2606-2613.

Lim R, Stathopoulos CE, Golding JB. Effect of edible coatings on some quality characteristics of sweet cherries. Int Food Res J. 2011. 18:1237-1241.

Maftoonazad N, Ramaswamy HS. Postharvest shelf-life extension of avocados using methyl cellulose-based coating. LWT. 2005. 38:617-624.

Martínez-Romero D, Alburquerque N, Valverde JM, Guillén F, Castillo S, Valero D, et al. Postharvest sweet cherry quality and safety maintenance by Aloe vera treatment: a new edible coating. Postharvest Biol Technol. 2006. 39:93-100.

Pérez-Gago MB, González-Aguilar G, Olivas GI. Edible coatings for fruits and vegetables. Stewart Postharvest Rev. 2010. 6:114.

Razavi SMA, Mortazavi SA, Matia-Merino L, Hosseini-Parvar SH, Motamedzadegan A, Khanipour E. Optimisation study of gum extraction from basil seeds (Ocimum basilicum L.). Int J Food Sci Technol. 2009. 44:1755-1762.

Ribeiro C, Vicente AA, Teixeira JA, Miranda C. Optimization of edible coating composition to retard strawberry fruit senescence. Postharvest Biol Technol. 2007. 44:63-70.

Ruiz-Martínez J, Aguirre-Joya JA, Rojas R, Vicente A, AguilarGonzález MA, Rodríguez-Herrera R, et al. Candelilla wax edible coating with Flourensia cernua bioactives to prolong the quality of tomato fruits. Foods. 2020. 9:1303. https://doi.org/10. 3390/foods9091303

Saekow M, Naradisorn M, Tongdeesoontorn W, Hamauzu Y. Effect of carboxymethyl cellulose coating containing ZnO-nanoparticles for prolonging shelf life of persimmon and tomato fruit. J Food Sci Agric Technol. 2019. 5:41-48.

Sganzerla WG, Ribeiro CPP, Uliana NR, Rodrigues MBC, da Rosa $\mathrm{CG}$, Ferrareze JP, et al. Bioactive and $\mathrm{pH}$-sensitive films based on carboxymethyl cellulose and blackberry (Morus nigra L.) anthocyanin-rich extract: a perspective coating material to improve the shelf life of cherry tomato (Solanum lycopersicum L. var. cerasiforme). Biocatal Agric Biotechnol. 2021. 33:101989. https://doi.org/10.1016/j.bcab.2021.101989.

Shwartz E, Glazer I, Bar-Ya'akov I, Matityahu I, Bar-Ilan I, Holland $\mathrm{D}$, et al. Changes in chemical constituents during the maturation and ripening of two commercially important pomegranate accessions. Food Chem. 2009. 115:965-973.

Srinivasa PC, Harish Prashanth KV, Susheelamma NS, Ravi R, Tharanathan RN. Storage studies of tomato and bell pepper using eco-friendly films. J Sci Food Agric. 2006. 86:1216-1224.

Toğrul H, Arslan N. Extending shelf-life of peach and pear by using CMC from sugar beet pulp cellulose as a hydrophilic polymer in emulsions. Food Hydrocoll. 2004. 18:215-226.

Yaman Ö, Bayoundurlt L. Effects of an edible coating and cold storage on shelf-life and quality of cherries. LWT. 2002. 35:146150.

Zapata PJ, Guillén F, Martínez-Romero D, Castillo S, Valero D, Serrano M. Use of alginate or zein as edible coatings to delay postharvest ripening process and to maintain tomato (Solanum lycopersicon Mill) quality. J Sci Food Agric. 2008. 88:1287-1293.

Zhu Y, Li D, Belwal T, Li L, Chen H, Xu T, et al. Effect of nano$\mathrm{SiOx} /$ chitosan complex coating on the physicochemical characteristics and preservation performance of green tomato. Molecules. 2019. 24:4552. https://doi.org/10.3390/molecules 24244552 